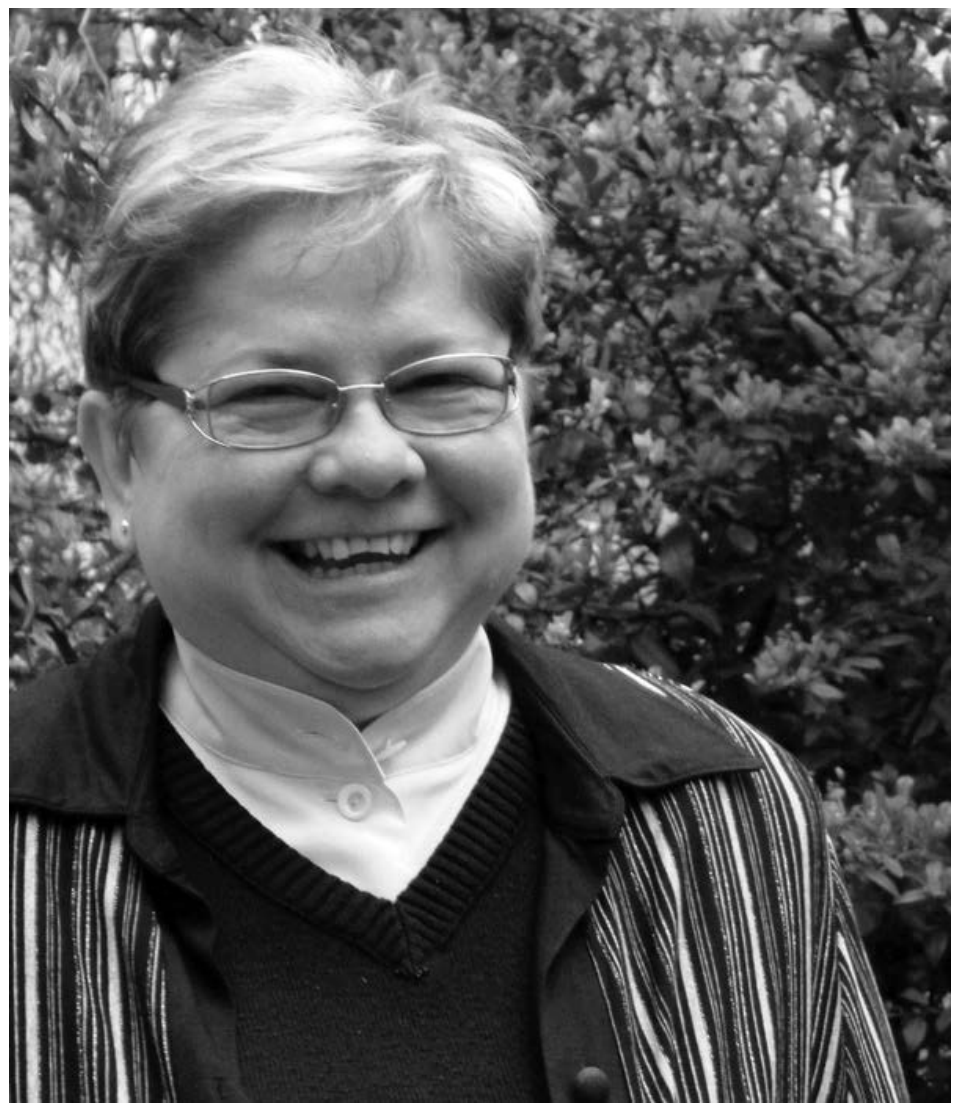





\section{Miluše Juříčková feiert ihr Lebensjubiläum}

Im Jahre 2016 begeht unsere Kollegin Doz. PhDr. Miluše Juř́ičková, CSc., Leiterin der nordistischen Abteilung des Instituts für Germanistik, Nordistik und Nederlandistik der Philosophischen Fakultät der Masaryk-Universität in Brünn, ihren 60. Geburtstag.

Die Jubilarin hat, nach dem Absolutorium der Mittelschule, an der Philosophischen Fakultät der Masaryk-Universität (damals J.E. Purkyně-Universität) die Fächer Norwegisch, Englisch und Deutsch studiert. Beendet hat sie das Studium im Jahre 1980 mit der Diplomarbeit „Georg Brandes und die norwegische Literatur der 80er Jahre des 19. Jahrhunderts“. Schon damals war es klar, dass sie sich weiter insbesondere der norwegischen Literatur und Kultur widmen wird.

Sie arbeitete allerdings zuerst als Bibliothekarin und Übersetzerin an der Hochschule für Veterinärmedizin (1982-84) und als Fachlehrerin an der Sprachschule in Brünn (1984-1985). Seit 1986 ist sie am obengenannten Institut für Germanistik, Nordistik und Nederlandistik tätig.

In diesem Institut konnte sie an eine lange Tradition anknüpfen. Vor allem denke ich an den Altgermanisten Prof. Leopold Zatočil, der sich nicht nur mit der deutschen mittelalterlichen Literatur beschäftigte, sondern auch mit der skandinavischen. Und unter anderem hat er (in einer vorbildlichen Edition, mit ausführlichen Kommentaren) die Volsunga Saga ins Tschechische übertragen. Sehr bedeutend war dann die Gestalt des Lehrers von Miluše Juříčková, von Prof. Josef B. Michl. Der widmete sich vornehmlich (in den 70er und 80er Jahren) der norwegischen Zweisprachigkeit und der Persönlichkeit von Björnson, war aber auch ein sehr fruchtbarer Übersetzer. Sein Verdienst war es, dass man Norwegisch seitdem als Sonderfach studieren konnte.

An diese Tradition, wie schon erwähnt, hat die Jubilarin erfolgreich angeknüpft. Im Jahre 1993 hat sie eine Dissertation zum Thema „Reflexion und Dokument. 
Der norwegische Roman über den zweiten Weltkrieg in den Jahren 1945-1966“ verteidigt. Und im Jahre 2012 hat sie sich habilitiert mit einer Arbeit über Sigrid Undset („Zwei Horizonten. Sigrid Undset und ihre tschechische Rezeption“), in der sie sich größtenteils der Aufnahme der Dichterin im tschechischen Kontext gewidmet hat.

Im derselben Jahr wurde sie zur Dozentin ernannt. Als Pädagogin konzentriert sie sich auf skandinavische und norwegische Literatur des 20. Jahrhunderts, insbesondere auf die zeitgenössischen Autoren und Genres, auf die Jugendliteratur, selbstverständlich ebenfalls auf Sigrid Undset. Sie befasst sich aber auch mit Translatologie und Komparatistik. Das hängt natürlich größtenteils mit ihrer eigenen übersetzerischen Tätigkeit zusammen. Seit 2009 ist sie Mitglied des Verbandes der tschechischen Übersetzer und hat zahlreiche Werke aus dem Norwegischen ins Tschechische übertragen, sowohl Belletristik als auch Fachtexte.

Unermüdlich engagiert sie sich als Vermittlerin zwischen Norwegen und Tschechien, vor allem auf dem Gebiet der Kultur. Es handelt sich praktisch um zahlreiche Vorträge und Artikel sowohl in Tschechien als auch in Norwegen, um Vorbereitung verschiedener Ausstellungen u.a.m. Für außerordentliche Verdienste auf diesem Feld wurde sie im Jahre 2003 mit dem norwegischen königlichen Verdienstorden ausgezeichnet und zur Ritterin dieses Ordens geschlagen.

Erwähnt werden muss auch ihre Tätigkeit in verschiedenen Verbänden (wie z.B. Nordische Gesellschaft) und ihre aktive Teilnahme an zahlreichen renommierten internationalen Tagungen (International Association for Scandinavian Studies u.a.m.).

Das ist eine höchst positive Bilanz. Bei der Jubilarin wollen wir uns bedanken für alles, was sie bisher für die tschechische Nordistik getan hat. Und im Namen aller ihrer Mitarbeiter, Studenten und Absolventen möchten wir ihr für die kommenden Jahre viel Erfolg in ihrer wissenschaftlichen Arbeit, feste Gesundheit und Glück im persönlichen Leben wünschen.

Jiří Munzar 